Accepted

22. 08.2021

Revised

01. 09. 2021

Published

29. 10. 2021

Keywords

the right

to self-determination, proportionality of the restriction,

mandatory

vaccinations,

conditional

marketing

authorisation,

vaccination

policy

\title{
COMPUlsory VACCINATIONS AgAINST COVID-19 VERSUS THE RIGHT TO RESPECT FOR PRIVATE LIFE
}

\author{
Katarzyna Miaskowska-Daszkiewicz \\ The John Paul II Catholic University of Lublin, Faculty of Law, Canon Law and \\ Administration, Department of Administrative Law, Lublin, Poland. \\ E-mail: katarzyna.miaskowska-daszkiewicz@kul.pl \\ CORRESPONDING AUTHOR \\ katarzyna.miaskowska-daszkiewicz@kul.pl
}

\begin{abstract}
The development and marketing authorisation of COVID-19 vaccines has given the authorities a muchanticipated instrument to fight a pandemic. At the same time, however, for the extinction of the epidemic to become real, according to epidemiologists' estimates, the threshold of herd immunity must reach the value of 50-70 percent. To ensure mass vaccination, it should be considered whether a compulsory vaccination against COVID-19 would be an acceptable solution. It is a sensitive issue in the context of the right to self-determination, guaranteed both in Article 8 European Convention on Human Rights, as well as most modern constitutions. The aim of this paper is to investigate whether the compulsory vaccination against COVID-19 could be the next step in the fight against the pandemic. In particular, whether the current approach of the ECHR and national courts to compulsory vaccination can be considered adequate in relation to COVID-19 vaccines with a conditional marketing authorisation.
\end{abstract}




\section{$1 \quad$ Introduction}

Even though the third decade of the 21 st century begins and although medicine has made enormous progress, we are still threatened by epidemics. Diseases previously considered eliminated are returning. New strains of bacteria and viruses appear, and antibiotic resistance causes old drugs to lose their effectiveness. Against this backdrop, at the end of 2019, the first cases of infection with a new, previously unknown coronavirus, causing the disease called COVID-19, were identified in China.

The scale of the speed of spread of the new virus is evidenced by the fact that by mid-March 2020, more than 150 countries had reported cases of COVID-19. At the time this paper was written, there were more than 210 million confirmed cases of COVID-19 worldwide $^{1}$, with the proviso that this is the number resulting from the tests carried out, while the actual number of infections is certainly higher.

Early in the pandemic's global transmission, Director-General of the WHO Dr. Tedros Adhanom Ghebreysus said:

All countries must strike a fine balance between protecting bealth, minimising economic and social disruption, and respecting buman rights. This is not just a public health crisis, it is a crisis that will touch every sector-so every sector and every individual must be involved in the fight. ${ }^{2}$

By formally declaring COVID-19 to be a global pandemic, during the same conference, Dr. Adhanom stipulated that it would be necessary to adopt preventative and reactionary health and safety measures that would ultimately reshape everyday life for people worldwide.

\footnotetext{
${ }^{1}$ Coronavirus COVID-19 Global Cases by the Center for Systems Science and Engineering (CSSE) at John Hopkins University, https://gisanddata.maps.arcgis.com/apps/dashboards/bda7594740fd40299423467b48e9ecf6.

2 WHO Director-General's Dr. Tedros Adhanom opening remarks at the Mission briefing on COVID-19 - 12 March 2020. https://www.who.int/director-general/speeches/detail/who-director-general-s-opening-remarks-atthe-mission-briefing-on-covid-19---12-march-2020.
} 
Indeed, the spread of the pandemic and the need to face its consequences has forced national governments to increasingly intensify restrictions. Travel bans, social distancing, mandating the use of face masks in public spaces, quarantines, restrictions on gatherings, contact tracing and many other COVID-related measures adopted around the world have breached or constrained human rights. These measures have severly limitated, among other things, the freedom of movement, the right to personal liberty, the freedom of assembly and association, the right to a private life, the right to manifest one's belief or religion, the right to work, the right to education, and the right to healthcare (limited access to health services not related to COVID-19) (Sekalala et al., 2020, passim, Spadaro, 2020, passim, Lebret, 2020, passim). ${ }^{3}$

The European Parliament has discovered and reported violations of fundamental rights and democratic principles due to the COVID-19 pandemic. In response to these disturbing findings, it formulated resolution of 13 November 2020 on the impact of COVID-19 measures on democracy, the rule of law and fundamental rights $(\underline{2020 / 2790(R S P)})$.

\section{Marketing authorisation of COVID-19 vaccines}

Vaccinations, as with most medicinal products, have developed incrementally, starting in their infancy as experimental medical ventures and over time maturing into commonly accepted lifesavers (Allen, 2007: 27).

Based on many years of experience utilizing vaccines in the fight against various infectious diseases, the natural direction of development of the pharmaceutical industry since the outbreak of the pandemic has been the search for a vaccine formula to provide immunity against COVID-19.

A vaccine is a medicinal, immunological product that is used to achieve active immunity (Article 1 Paragraph 4a of the Directive 2001/83/EC). Like any medicinal product (produced by an industrial method) in the EU, a vaccine should demonstrate therapeutic efficacy, safety and appropriate quality. These criteria should, in turn, be confirmed by the decision of the competent regulatory authorities (national or EU

\footnotetext{
${ }^{3}$ More examples from around the world at: https: / $/$ www.icnl.org $/$ covid19tracker/?location=\&issue=10\&date=\&type $=$
} 
- Article 6 of the Directive 2001/83/EC). Regardless of the type of registration procedure (national or centralized, carried out pursuant to Regulation 726/2004), the scope of documentation attached to the application for marketing authorization of the vaccine is specified in Annex 1 to Directive 2001/83/EC and covers the results of clinical trials confirming the safety and efficacy of the drug.

Given the unprecedented nature of the disease and the scale and effects of its spread, the authorities used the Conditional Marketing Authorisation (CMA) scheme introduced by Commission Regulation 507/2006. A CMA is one of the EU's regulatory mechanisms for facilitating early access to medicines that fulfil an unmet medical need, including in emergency situations such as the current pandemic. A CMA is a formal authorisation for the use of the vaccine, covering all batches produced for the EU, and which provides a robust assessment to underpin vaccination campaigns.

In order to comprehend how CMA works it is necessary to understand how clinical trials work, including their various phases. Clinical trial phases are steps in the research to determine if an intervention would be beneficial or detrimental to humans. There are four clinical trial phases. Studies conducted in Phase I typically involve the following aspects: an estimation of initial safety and tolerability, pharmacokinetics, and an assessment of pharmacodynamics. Phase II usually considers and explores the therapeutic efficacy of the vaccine in patients. Phase III is usually to demonstrate, or confirm, the therapeutic benefit of the vaccine. Studies in Phase IV are performed after drug approval and are focused on observing any rare of long-term effects of the drug in a much larger population of patients and over a much longer period of time. Phase IV studies are often important for optimising the drug's use. In a standard clinical trial scenario, the phases of the research follow one another sequentially.

In the standard workflow of clinical trials, the marketing authorization application is submitted after the completion of the first three phases. The application includes all the results obtained in the initial phases, which are then analyzed by the European Medicines Agency (EMA) with a view to the preparation of an assessment report and recommendation for the Commission. Phase III clinical trials can take an average of three to five years to complete and are the most expensive of all phases of clinical trials. 
At the beginning of the pandemic, when the Chinese first revealed the genetic code of the SARS-CoV-2 virus, research teams worldwide immediately began work on building a vaccine. At the same time, they did not start completely from scratch. Vector vaccines (AstraZeneca and Johnson \& Johnson chose this technology) are vaccines that are already used in humans. The Ebola vaccine, which is currently used in Africa, is an example of a vector vaccine. The Ebola vaccine, although based on a different viral vector, nevertheless is a safe and very effective vaccine used for extinguishing Ebola outbreaks. The Ebola vaccine is relatively new. Scientists, building upon the research already carried out in connection with the Ebola vaccine,were able to redesign these existing vaccines very quickly and and to specifically target them against COVID-19. This was similar to the case involving vaccines based on mRNA technology (Pfizer/BioNTech and Moderna preparations), on which research has been carried out for years, because there were attempts to develop vaccines against SARS (in 2002) and MERS (in 2012) coronaviruses. The models developed at that time were quickly adapted to the preparation of vaccines against COVID-19.

The current COVID-19 vaccines have been conditionally authorized based on all required laboratory, non-clinical animal studies, Phase I and II clinical trials, and periodic evaluations of the most advanced Phase III clinical trials. An authorization is granted when the benefits of the immediate availability of a vaccine to patients outweigh the risks of the fact that not all data from ongoing Phase III trials are yet available. Vaccines for COVID-19 were approved after reviewing the partial results of a Phase 3 clinical trial (studies lasted 2-3 months), which confirmed the clinical efficacy and safety of the vaccine in protecting against the symptoms of COVID-19. Phase II clinical trials are, however, continued to assess parameters such as the duration of vaccine protection. For example, about nine months after the COVID19 pandemic was declared, on December 21, 2020, the European Commission granted CMA, following the EMA's positive opinion, to BioNTech COVID-19 mRNA vaccine (nucleoside-modified) BNT162b2 (Comirnaty). ${ }^{5}$ Phase III trials for this vaccine started in August 2020 and will run for 24 months under the risk management plan, to assess the long-term safety and efficacy of the vaccine. ${ }^{6} \mathrm{CMA}$

\footnotetext{
${ }^{4}$ EMA Comirnaty assessment report https://www.ema.europa.eu/en/documents/assessment-report/comirnatyepar-public-assessment-report_en.pdf

${ }^{5}$ https://www.ema.europa.eu/en/documents/product-information/comirnaty-epar-product-information_en.pdf ${ }^{6}$ EMA Comirnaty risk management plan https://www.ema.europa.eu/en/documents/rmp/comirnaty-epar-riskmanagement-plan_en.pdf
} 
is valid for one year and can be renewed annually. The CMA holder is also obliged to fulfil additional obligations, which may include completing ongoing or new studies or collecting additional data to confirm that the medicine's benefit-risk balance remains positive.

\section{$3 \quad$ Right to respect for private life}

Protective vaccination is the administration of a vaccine against an infectious disease for the purpose of artificial immunization. It is therefore a "clear example of pure prevention treatment" and as such "can only be carried out with informed consent, except under very extraordinary circumstances. This rule is developed in international bioethics declarations, human rights instruments and human rights jurisprudence and doctrine" (Acosta, 2015).

Article 5 of the Oviedo Convention of 1997 establishes a general rule with regard to medical intervention: "An intervention in the health field may only be carried out after the person concerned has given free and informed consent to it. This person shall beforehand be given appropriate information as to the purpose and nature of the intervention as well as on its consequences and risks".

Additionally, the Explanatory Report (ER) to the Oviedo Convention explains "Article $5 \ldots$ deals with consent and affirms at the international level an already wellestablished rule that is that no one may in principle be forced to undergo an intervention without his or her consent. Human beings must therefore be able freely to give or refuse their consent to any intervention involving their person. This rule makes clear patients' autonomy in their relationship with health care professionals and restrains the paternalist approaches which might ignore the wish of the patient. The word 'intervention' is understood in its widest sense, as in Article 4 - that is to say, it covers all medical acts, in particular interventions performed for the purpose of preventive care, diagnosis, treatment, rehabilitation or research"7

\footnotetext{
${ }^{7}$ Council of Europe, Explanatory Report to the Convention for the Protection of Human Rights and Dignity of the Human Being with Regard to the Application of Biology and Medicine, Dir/Jur(97)5, par. 34 (May, 1997). Available at: https://rm.coe.int/CoERMPublicCommonSearchServices/DisplayDCTMContent?documentId=09000016800cc de5.
} 
The European Court of Human Rights (ECHR) has reaffirmed that informed consent is required for any medical intervention under the Oviedo Convention, and its absence represents a violation of the right to respect for private life, protected by Article 8 of the Convention on Human Rights. ${ }^{8}$

Referring directly to immunization, the ECHR pointed out that "[c]ompulsory vaccination - as an involuntary medical treatment - amounts to an interference with the right to respect for one's private life, which includes a person's physical and psychological integrity, as guaranteed by Article 8(1)" (Solomakhin v Ukraine, para 33). ${ }^{9}$

The crowning achievement of the ECHR's jurisprudence in the area of examining the compliance of compulsory preventive vaccinations with the right to respect for private life is the judgment on Vavricke and others v. the Czech Republic, which will be discussed in point 4.2 .

\section{Compulsory COVID-19 vaccination as a next step in the fight with the pandemic?}

\subsection{Vaccinations policies}

With the success of the smallpox vaccine, discovered by E. Jenner ${ }^{10}$ at the end of the 18th century, coupled with the development of medical knowledge about the human immune system, the first mandatory vaccination policies appeared in the world. In 1871, the Parliament of England established the Vaccination Act, which made it mandatory for persons to go through the vaccination procedure. In 1874, Germany mandated the compulsory vaccination of all German children. The United States followed with Boston becoming the first city with a mandatory vaccination law in 1827 (Allen, 2007: 59-65).

\footnotetext{
${ }^{8}$ M.A.K. and R.K. v. United Kingdom (app. no. 45901/05 and 40146/06 - a blood test and photograph of a 9 year-old girl without her parent's permission); Solomakhin v. Ukraine (app. no. 24429/03 - vaccination against diphtheria against will of the adult patient).

${ }^{9}$ See also Boffa and others v. San Marino, app. no. 26536/95.

${ }^{10}$ Who has been said to be the father of modern vaccinations.
} 
Interestingly, even then, there was skepticism and opposition from some segments of the society to obligatory vaccination programs imposed by the authorities. Allen noted that the resistance in Britain was strong and eventually vaccination rates fell from 80 percent in 1898 to 18 percent in 1948 (Allen, 2007: 63-65).

The vaccination policies currently adopted by the authorities of individual countries are an element of their overall health policy, and are shaped by many factors, including international obligations. Of particular importance, The International Covenant on Economic, Social and Cultural Rights (ICESCR), adopted by the United Nations General Assembly on 16 December 1966 through General Assembly Resolution 2200A (XXI), guarantees all people their dignity and body integrity. However, the key element when evaluating human rights law generally, and the issue of mandatory vaccination policies in particular, lies within Article 12 of the Convention.

Article 12 is designed to guarantee that the parties to the Covenant take necessary steps to prevent, control and treat diseases whether epidemic, work-related, or endemic in order to make sure everyone may enjoy the optimal physical and mental health.

In addition, Article 11 of the European Social Charter of 18 October 1961states: "With a view to ensuring the effective exercise of the right to protection of health, the Contracting Parties undertake, either directly or in co-operation with public or private organisations, to take appropriate measures designed inter alia: (...) 3. to prevent as far as possible epidemic, endemic and other diseases".

Considering that preventive vaccinations are dedicated mainly to the pediatric segment of the population (i.e., children), it is also necessary to refer to Article 24 of United Nations Convenion on the Rights of the Child adopted by UN General Assembly on 20 November 1989. Its provision assumes that "States Parties recognize the right of the child to the enjoyment of the highest attainable standard of health" and they shall take appropriate measures to achieve this goal. 
The results of the research in the literature show that in the world, and even in the region, there is no uniform approach by the authorities regarding obligatory vaccinations. It is generally accepted, however, that vaccinations per se are recognized as one of the most important tools of primary prevention (Kraljić \& Kobal, 2020: 432; Haverkate et al., 2018).

It is up to the national authorities to decide whether vaccination against a particular disease is compulsory or only recommended. However, this is not entirely a discretionary decision, given that the imposition of an obligation to vaccinate involves an interference with the freedom to decide about one's life.

In the commentary to a survey on vaccination policy in European countries, Haverkate et al. emphasize that "the issue of mandatory versus recommended vaccinations has been widely discussed in Europe" (Haverkate et al., 2018). In fact, while national vaccination policies may differ (Kraljić \& Kobal, 2020: 434-438), these policies are not static. This is evidenced by the fact that in response to the changing epidemic situation, vaccine development, changes in risk groups, clear negative effects caused by vaccination, or changes in vaccine effectiveness, countries are modifying their approaches to vaccination in an effort to confront these always changing variables. There is even a trend to tighten regulations in response to low immunization levels (Kraljić \& Kobal, 2020: 444-456).

For example, by a decree of 7 June $2017^{11}$ in Italy, the number of diseases against which vaccination is compulsory in children was increased from four to ten. ${ }^{12} \mathrm{In}$ France, where the vaccination of children against poliomyelytis, diphtheria and tetanus was already compulsory, in 2018 the list of compulsory vaccinations was increased for eight additional infectious diseases. ${ }^{13}$

In the Federal Republic of Germany, despite all the awareness campaigns about the benefits of vaccination, the measles vaccination gap has proved to be still too large. According to the Robert Koch Institute's estimates of vaccination rates, while 97.1 percent of new students in Germany received their first measles vaccine, there were

\footnotetext{
${ }^{11}$ Disposizioni urgenti in materia di prevenzione vaccinale (17G00095); GU Serie Generale, n. 130.

12 http: // www.salute.gov.it / portale / vaccinazioni / dettaglioContenutiVaccinazioni.jsp? lingua $=$ italiano \& id $=4829 \&$ area $=$ vaccinazioni $\&$ menu $=$ vuoto.

13 https://solidarites-sante.gouv.fr/prevention-en-sante/preserver-sa -sante / vaccination / vaccins-obligatoires / article / vaccinations-obligatoires-ce-qui-change-au-1er-juin-2018
} 
large regional differences in the decisive second measles vaccine. Consequently, the benchmark vaccination rate of 95 percent, desirable for achieving herd immunity to protect society, still has not been achieved at the federal level. In addition, taking into account the dynamic increase in the number of measles cases (501 cases were recorded by October 2019, while in the entire year 2018 there were only 544 cases of measles), a legislative initiative was launched to introduce mandatory vaccination against measles in the pediatric segment of the population. On February 10, 2020, the German legislator adopted the Act on Protection against Measles and Strengthening Vaccination. ${ }^{14}$ This Act entered into force on March 1, 2020 and requires vaccinations for all children over the of age of one attending kindergarten or school. Under the Act, parents are required to submit a vaccination certificate (or the child's previously acquired immunity to measles, which is a condition for exemption from vaccination), subject to a fine of up to EUR 2,500.15

The central tenet underpinning the obligation to vaccinate is to cover the widest possible part of the population with prophylaxis in the field of infectious diseases. This vaccination strategy is comprised of both individual and social dimensions. On the one hand, the vaccinated person is himself protected against the disease; the administered vaccine, imitating a natural infection, leads to the development of immunity analogous to that which the body acquires upon contact with the actual pathogen. On the other hand, the presence of people immunized against a given disease in the population reduces the likelihood of non-immune people developing this disease. This eventually builds what is known variously as herd, group or population immunity. In sum, vaccination protects not only the vaccinated person, but also the weakest in society, who cannot be vaccinated due to contraindications, because they are too young to be vaccinated (infants), they suffer from chronic diseases or their condition is excluded, for example, after transplantation.

\footnotetext{
${ }^{14}$ Das Gesetz für den Schutz vor Masern und zur Stärkung der Impfprävention, BGBl 2020 Teil I Nr. 6, S. 148.

15 Several parents filed constitutional complaints with the German Federal Constitutional Court in opposition to the Measles Protection Act. The complaints have not yet been decided. In two of the pending proceedings, the complainants had also filed applications for an interim order requesting the provisional suspension of the law. By a decision of May 5, 2020, the German Federal Constitutional Court rejected the applications for an interim order (file no. $1 \mathrm{BvR} 469 / 20$ und $1 \mathrm{BvR} 470 / 20$ ). The agenda of the Federal Constitutional Court provides for a substantive decision on the issue of the obligation to vaccinate against measles sometime in 2021 .
} 
According to the Polish National Institute of Public Health "the herd immunity threshold is defined as the percentage of people immunized in a population at which the number of new infected begins to decline, typically $90-95$ percent of the immune population is required. However, the percentage of immunized immunized people varies from disease to disease. For example, in the case of measles this 'safety threshold' is as high as 95 percent, for whooping cough it is estimated at 92-94 percent, diphtheria and rubella at 83-86 percent, mumps at 75-86 percent. Which means that so many people in the population must be resistant to a given disease in order not to get infected on a larger scale". ${ }^{16}$

The effectiveness of compulsory preventive vaccinations is confirmed by both the statistics presented by the Polish sanitary services and the data of the WHO, which conducts monitoring. ${ }^{17}$ For example, in 1952, before the diphtheria vaccination was introduced in 1961, 40,654 people fell ill with the disease (registered cases); currently there are no cases of this disease in Poland. 196,109 cases of measles were recorded in Poland in 1973 ${ }^{18}$, compulsory vaccinations were introduced in 1975, and in 2019 $-1,492$ cases, the number of which is four times higher than in $2018 .{ }^{19}$

At the same time, it must be recognized that there are various explanations for some countries not legislating compulsory, preventive vaccinations programs. In some countries, for example, citizens may well appreciate that there are certain risks associated with vaccines, but have greater awareness of the benefits of preventive vaccinations, believe those benefits substantially outweigh the risks, and simply place a higher level of trust in vaccination than in other countries, which in turn translates into higher vaccination levels. According to findings in the report "The level of confidence in vaccines in the EU in 2018" prepared at the request of the European Commission by scientists from the London School of Hygiene \& Tropical Medicine ${ }^{20}$, Poland is one of the countries with the lowest confidence in vaccines. In Poland, only 75.9 percent of respondents agreed with the statement that vaccinations are important for children; 74.9 percent - considered the effectiveness of the vaccines; 72.4 percent said vaccines were safe; and, only 59.3 percent said

\footnotetext{
${ }^{16}$ https://szczepienia.pzh.gov.pl/wszystko-o-szczepieniach/co-to-jest-odpornosc-zbiorowiskowa/

${ }^{17}$ For Poland, see statistics covering the years 1980-2018:

http://apps.who.int/immunization_monitoring/globalsummary/incidences?c) $=$ POL

18 https://szczepienia.pzh.gov.pl/wp-content/uploads/2019/12/Sz szczepieniadzia\%C5\%82aj.png

${ }^{19}$ https://szczepienia.pzh.gov.pl/faq/jak-wiele-zachorowan-na-odre-wystepuje-obecnie-w-polsce /

20 https://ec.europa.eu/health/sites/health/files/vaccination/docs/2018_vaccine_confidence_en.pdf
} 
vaccines were consistent with religious beliefs. It should therefore be reasonably assumed that the lifting of the vaccination requirement for certain diseases could lead to their resurgence.

The current situation regarding the risk of recurrence of vaccine-preventable diseases in Europe is suboptimal. The increased incidence of measles is a case in point. According to the European Center for Disease Prevention and Control, unprecedented outbreaks of measles and other vaccine-preventable diseases are occurring in several EU countries due to insufficient immunization coverage (Czechowicz, 2021: 81-82). The European Commission has therefore taken the initiative to adopt Council Recommendations on enhanced cooperation in the fight against vaccine-preventable diseases (COM (2018) 244 final). This document, addressed to the EU Member States, defines the scope of cooperation and tasks to be carried out in order to improve the vaccination status and ensure that everyone in the EU has access to vaccination. It is expected that the cooperation between the Member States of the European Union will be enhanced in the field of preventive vaccination. 25 recommendations were presented. Implementing these recommendations will, in the opinion of the European Commission, contribute to better control of diseases that can be prevented by vaccinationby increasing the coverage of vaccination.

\subsection{Case Vavričcka and others v. the Czech Republic}

On the 8th of April, the Grand Chamber of the ECHR issued its judgment on Vavricke and others v. the Czech Republic which confirmedviews of ECHR on compulsory vaccinations in view of the guarantee of the right to respect for private life under Article 8 of the Convention on Human Rights.

This case originates from six applications which were joined. The first applicant, Mr. Vavřička, was fined for having refused to have his two adolescent children vaccinated against three diseases included in the compulsory vaccination programme in force in the Czech Republic. The other five applicants were children, whose parents, to various degrees, had failed to comply with the vaccination scheme. As a result, the children were denied admission to pre-school nurseries. 
The ECHR confirmed that "compulsory vaccination, as an involuntary medical intervention, represents an interference with the right to respect for private life" (para. 263), which requires an examination of whether such an interference can be justified under Article 8(2) of the Convention on Human Rights.

The formal premise for limiting the right to privacy is its introduction via an accessible and foreseeable legal provision (paras. 266-271). Then it should be verified whether the introduced restriction meets the values indicated in Article 8(2) of the Convention on Human Rights, namely: the interests of national security, public safety or the economic well-being of the country, for the prevention of disorder or crime, for the protection of health or morals, or for the protection of the rights and freedoms of others.

The next step in the ECHR's analysis was to assess the necessity of the adopted interference in a democratic society.

Following an earlier view - expressed in the case Solomakhin v. Ukraine - the ECHR reaffirmed that desirable by convention "necessity" should be examined by answering the following questions: 1) whether public health considerations necessitated the control of the spreading of infectious diseases; and 2) whether necessary precautions had been taken with regard to the suitability of vaccination for the individual case at hand (para. 36).

In the Vavricke and others case, the considerations concerning the assessment of what constitutes "necessity in a democratic society" were expanded by the ECHR to include the need to verify: 1) the scope of the Margin of Appreciation of the evaluated state (paras. 276-280), 2) the existence of a pressing social need and relevant and sufficient reasons necessitating the interference (paras. 281-289) and 3) the proportionality of the interference with the legitimate aim pursued (paras. 290309).

In the V avricke and others case, employing these considerations, the ECHR concluded that although the right to respect for private life had been violated, due to the conventionally legitimate aim of health protection, it was purposeful and necessary, while maintaining proportionality sensu stricto. Thus, the mandatory vaccination of 
children has been deemed compliant with Article 8 of the Convention on Human Rights.

\subsection{Confrontation of premises justifying the introduction of compulsory preventive vaccinations in the context of vaccination against COVID-19}

Turning to the analysis of the judgment in the Vavricka and others case in the context of the possible introduction of compulsory vaccination against COVID-19, it should be emphasized that the ECHR stipulated that this case "relates to the standard and routine vaccination of children against diseases that are well known to medical science". As might be expected - considering that the ECHR ruled during a pandemic, aware of the public debate on compulsory vaccination against COVID19 - such statements were intended to rule out the temptation to extrapolate the findings made by the ECHR on this case to other vaccines, not excluding vaccination against COVID-19.

However, some elements of the ECHR's reasoning in the analyzed case seem relevant for the assessment of compliance with the right to respect for private life of the possible introduction of an obligatory vaccination against COVID-19.

Firstly, recognizing that there is no international consensus on adopting a specific vaccination policy (compulsory or voluntary vaccination) and, at the same time, that immunization is widely recognized as an effective instrument in the fight against infectious diseases, the ECHR concluded that countries enjoy a wide margin of autonomy on the matter (para. 280). As Katsoni emphasizes "This conclusion was also influenced by the value of social solidarity and 'the duty to protect the health of all members of society, particularly those who are especially vulnerable with respect to certain diseases and on whose behalf the rest of the population was asked to assume a minimum risk in the form of vaccination"" (Katsoni, 2021).

Therefore, it it is important to recognize that the rationale underpinning compulsory vaccination regimes is the achievement of group immunity and, consequently, protection of the public health. Meanwhile, in the case of vaccination against COVID-19, reaching a herd-immunity threshold (in the absence of obligatory schemes) looks unlikely "because of factors such as vaccine hesitancy, the emergence 
of new variants and the delayed arrival of vaccinations for children" (Aschwanden, 2021). Of course, it is not the role of the lawyer to assess the effectiveness of vaccines and the epidemic realities. For this reason, the ECHR relied on scientific consensus to drive its judgment and endorsed science-based policy measures aimed at the protection of life and health, which were given precedence over individual wishes and preferences.

Based on the considerations discussed in section 2 of this paper, it should be recalled that all COVID-19 vaccines authorized in the EU are conditional, as their clinical trials have not been completed. The ongoing monitoring of the results of further stages of Phase III clinical trials will continue to shed new light on the safety profile of vaccines. For example, on July 1, 2021, the European Commission published updated information sheets covering the Summary of Product Characteristics, Labeling and Package Leaflet of Astra Zeneca COVID-19 Vaccines. ${ }^{21}$ The introduced changes concern, among others, security profile summaries. Information has been added that informs the reader that various side effects may occur after administration of the vaccine.

The following side effects have been included in the SmPC and package leaflet of AstraZeneca: lethargy, abdominal pain, urticaria, angioedema, pain in the extremities, flu-like illness, and asthenia.

Perhaps people suffering from preexisting deep vein thrombosis, if they had known this information before receiving a vaccination, would not have been vaccinated with this particular preparation. This situation casts doubt on the safety of the vaccine, because in a year it may turn out that after one million questionnaires are obtained, the evidence shows that the vaccine impairs the functioning of the body. Introducing mandatory vaccination against COVID-19 at this stage would, in my view, breach the proportionality principle.

\footnotetext{
21 https://www.ema.europa.eu/en/documents/product-information/vaxzevria-previously-covid-19-vaccine-
} astrazeneca-epar-product-information_en.pdf 
When considering the legitimate aim of the restrictions, which is the protection of public health, there currently are many factors which, when considered in their entirety, makes it impossible to assume that it is possible to achieve group (i.e., herd) immunity. First, it is still unclear whether vaccines prevent infection and transmission (Cavaleri et al., 2021, p. 356), and according to scientists "Herd immunity is only relevant if we have a transmission-blocking vaccine. If we don't, then the only way to get herd immunity in the population is to give everyone the vaccine" (Aschwanden 2021). Scientific research does not clearly indicate how long immunity to coronavirus lasts after vaccination, and thus whether, and how often, the vaccination should be repeated.

The second obstacle to achieving group immunity against COVID-19, given human mobility, is the variation in vaccine availability across the world. Unfortunately, it is the lack of solidarity that makes us collectively do only as well as our weakest link. If populations in Third World countries are not vaccinated, rich countries can forget about the long-term break from COVID-19 (Sekalala et al., 2020: 5).

Third, the new SARS-CoV-2 variants contribute to the difficulty in achieving immunity herds. More specifically, the question rests with the effectiveness of vaccines developed for a particular variant at the beginning of the pandemic against the mutation of the coronavirus (Cavaleri et al., 2021: 356). Data published by the Israeli government suggest that the Pfizer BioNTech jab's efficacy against symptomatic infection fell from 94 percent to 64 percent after the delta variant began spreading in the country (Odenheimer \& Shepherd, 2021). Figures from Public Health Scotland published in The Lancet also show a drop in protection against symptomatic illness (Sheikh \& all, 2021: 2461-2462), from 92 percent against the alpha variant, which was first detected in the UK, to 79 percent against delta among people with two doses of the Pfizer/BioNTech vaccine. For the Oxford/AstraZeneca vaccine, the reduction was from 73 percent to 60 percent (Aschwanden, 2021).

Summarizing the findings, in my opinion, it cannot be reasonably argued today that vaccination against COVID-19 results in herd immunity, which protects weaker individuals who cannot (or do not want to) be vaccinated. Of course, based on the evidence that vaccines reduce disease symptoms, one could argue that widespread vaccination against COVID-19 will protect the healthcare system from collapse. 
However, is it not possible to achieve this goal through means that interfere less less with the right to privacy, such as by appropriate reorganization of the system to make it function more efficiently?

One should fully agree with the view expressed by Katsoni "that the measure of compulsory COVID-19 vaccinations will be compatible with the ECHR, if the vaccination is considered safe by the scientific community, it is only indirectly imposed through sanctions of a protective character with respect to conscience exceptions, necessary precautions are taken (prior assessment of potential contraindications in each case and monitoring of the vaccines in use), compensation is available in situations of injuries caused by the vaccine" (Katsoni, 2021). At the same time, it should be noted that as of today - due to the lack of complete data on the safety and efficacy profile of available vaccines against COVID-19 - such a decision by countries functioning in the Strasbourg human rights protection system would not meet the proportionality requirement. ${ }^{22}$

In the context of declared public health emergencies, there are examples of regulations providing authorities with various coercive powers, including the ability to impose vaccinations. For example, Western Australian's Public Health Act (2016, Section 157(1)(j)) allows the chief health officer (or a delegate) to "direct any person to undergo medical observation, medical examination or medical treatment or to be vaccinated" during a state of emergency. As the COVID-19 vaccine has not been ruled out, it can therefore reasonably be assumed that the cited provision also applies to this vaccine. However, this power relates to individual cases and cannot form the basis of a blanket policy in the country.

\section{$5 \quad$ Conclusion remarks}

The introduction of mandatory vaccinations has to be seen from two sides. Firstly, it must be viewed from the perspective of the authorities tasked with protecting human health. This goal can be achieved not only by the organization of the health care system in an institutional sense, but also by all instruments serving it, from environmental protection to the regulation of foodstuffs. The whole range of

\footnotetext{
${ }^{22}$ However, it cannot be ignored that some states declare introducing such an obligation for at least part of the society, more see Dyer, 2021.
} 
activities also includes vaccination policy, in particular, establishing a vaccination obligation in order to achieve group immunity.

On the other hand, however, the vaccination obligation undoubtedly interferes with the right to decide about our life (or the life of the person for whom we are legally responsible), depriving us of the possibility of effectively refusing the health service, which is vaccination.

After more than a year of experience in the fight against COVID-19, which in its dimension is an unprecedented phenomenon, we probably all realize that extraordinary times call for extraordinary measures. Nous somme en guerre, proclaimed French President Emmanuel Macron, announcing a series of aggressive measures to contain the spread of the COVID-19 pandemic. ${ }^{23}$

It is possible that mandatory vaccination against COVID-19 could be such an extraordinatory measure, a weapon in the fight against the pandemic.

In the light of the ECHR jurisprudence, when coupled with the existing data on vaccines (or rather in the absence of complete data), the introduction of compulsory vaccination against COVID-19 should be considered as a premature step, disproportionately interfering with the right to respect for private life.

\section{Legislation, Acts, Regulations and Court Decisions}

Commission Regulation (EC) No 507/2006 of 29 March 2006 on the conditional marketing authorisation for medicinal products for human use falling within the scope of Regulation (EC) No. 726/2004 of the European Parliament and of the Council (2006). Official Journal of the European Union, L92, pp. 6-9.

Convention for the Protection of Human Rights and Fundamental Freedoms, as amended by Protocols Nos. 11 and 14, of 4 November 1950 (hereinafter: Convention on Human Rights).

Convention for the Protection of Human Rights and Dignity of the Human Being with regard to the Application of Biology and Medicine: Convention on Human Rights and Biomedicine of 4 April 1997 in Oviedo.

Directive 2001/83/EC of the European Parliament and of the Council of 6 November 2001 on the Community code relating to medicinal products for human use. (2001). Official Journal of the European Union, L311, pp. 67-128 with amendments.

Public Health Act of Minister for Health of Western Australia No. 018 of 25 July 2016. https://www.legislation.wa.gov.au/legislation/prod/filestore.nsf/FileURL/mrdoc_44235.ht

\footnotetext{
23 The appeal of the President of the French Republic, Emanuel Macron, to the French of 16 March 2020, https://www.elysee.fr/emmanuel-macron/2020/03/16/adresse-aux-francais-covid19
} 
$\mathrm{m} /$ FILE/Public $\% 20$ Health $\% 20$ Act $\% 202016 \% 20-\% 20 \% 5$ B00-10-

00\%5D.html?OpenElement

Regulation (EC) No. 726/2004 of the European Parliament and of the Council of 31 March 2004 laying down Community procedures for the authorisation and supervision of medicinal products for human and veterinary use and establishing a European Medicines Agency. (2004). Official Journal of the European Union, L136, pp. 1-70 with amendments.

\section{References}

Acosta, J.I. (2015) Vaccines, informed consent, effective remedy and integral reparation: an integral human rights perspective, Vniversitas, 131, pp. 19-64, doi: 10.11144/Javeriana.vj131.vier.

Allen, A. (2007) Vaccine: The Controversial Story of Medicine's Greatest Lifesaver, 1st ed. (New York: W.W. Norton \& Company).

Aschwanden, C. (2021) Five reasons why COVID herd immunity is probably impossible, Nature, 591, pp. 520-522, doi: 10.1038/d41586-021-00728-2.

Cavaleri, M., Enzmann, H., Straus, S. \& Cooke, E. (2021) The European Medicines Agency's EU conditional marketing authorisations for COVID-19 vaccines, The Lancet, 397(10272), pp. 355357, doi: S0140-6736(21)00085-4.

Czechowicz, S. (2021) Legal guarantees for the protection of public health against the spread of infectious diseases - new challenges and threats, Medicine, Law \& Society, 14(1), pp. 77-94.

Dyer, O. (2021. Covid-19: Turkmenistan becomes first country to make vaccination mandatory for all adults, BMJ, 374, doi: 10.1136/bmj.n1766.

Fomina Yu, L. (2016) Protection of the Right to Respect for Private and Family Life in European Court of Human Rights, European Research Studies, 19(3B), pp. 97-110.

Haverkate, M. et al. (2012) Mandatory and Recommended Vaccination in EU, Iceland and Norway: Results of the VENICE 2010 survey on the ways of implemeting national vaccination programs, Eurosurveillance, 17(22), retrieved from: http://www.eurosurveillance. org/content/10.2807/ese.17.22.20183-en (9. 9. 2021).

Katsoni, S. (2021) What Does the Vavricke Judgment Tell Us About the Compatibility of Compulsory COVID19 Vacinations with the ECHR? Völkerrechtsblog, 21.04.2021, doi: 10.17176/20210421-100920-0.

Kraljić, S. \& Kobal, A. (2018) Verschärfung der Gesetzgebungsansätze zur Impfungen in ausgewählten Staaten, Zbornik Pravnog fakulteta u Zagrebu, 68(3-4), pp. 431-464.

Lebret, A. (2020) COVID-19 pandemic and derogation to human rights, Journal of Law and the Biosciences, 7(1), pp. 1-15, doi: 10.1093/jlb/lsaa015.

Odenheimer, A. \& Shepherd, D. (2021) Pfizer shot halts severe illness in Israel as delta spreads, Bloomberg, 5 July 2021, retrieved from: www.bloomberg.com/news/articles/2021-07-05/israelsees-decline-in-pfizer-vaccine-efficacy-rate-ynet-says (9. 9. 2021).

Sekalala, S., Forman, L., Habibi, R. \& Meier, B.M. (2020) Health and human rights are inextricably linked in the COVID-19 response, BMJ Global Health, 5, pp. 1-7, doi: 10.1136/bmigh-2020003359.

Sheikh, A., McMenamin, J., Taylor, B. \& Robertson, C., Public Health Scotland and the EAVE II Collaborators (2021) SARS-CoV-2 Delta VOC in Scotland: demographics, risk of hospital admission, and vaccine effectiveness, Lancet, 397, p. 2461-24622, doi: 10.1016/S01406736(21)01358-1 pmid:34139198.

Spadaro, A. (2020) COVID-19: Testing Limits of Human Rights, European Journal of Risk Regulation, 7 , pp. 1-9, doi: 10.1017/err.2020.27. 
